\title{
Spontaneous degeneration of germ cells in normal rat testis: assessment of cell types and frequency during the spermatogenic cycle
}

\author{
J. B. Kerr \\ Department of Anatomy, Monash University, Clayton, Melbourne, Victoria 3168, Australia
}

\begin{abstract}
Summary. The occurrence of degenerating germ cells in the cycle of the seminiferous epithelium was measured in testicular tissues from eight normal adult rats. Testes were perfusion fixed, embedded in epoxy resin and, after sectioning a total of 180 randomly selected blocks at $1 \mu \mathrm{m}$, stained sections were examined by light microscopy; all crosssectioned seminiferous tubules were categorized into one of 14 stages of the spermatogenic cycle. The number of degenerating cells per tubule was recorded in 2103 tubules. Degenerating germ cells were not detected at stages II-VI, and only rarely at stage VII ( $n=366$ tubules) in which one primary spermatocyte and one step 19 spermatid degenerated. All other stages exhibited a greater incidence of degenerative germ cells, particularly at stage XIV where, on average, the frequency of degenerating cells per round seminiferous tubule was about 40 times greater than at stage VII. The results indicated that, in the normal adult rat testis, the germ cells are least at risk of degeneration as they pass through stage VII.
\end{abstract}

Keywords: testis; spermatogenesis; germ cells; cell degeneration; rat

\section{Introduction}

The number of mature spermatids produced during the spermatogenic process is always less than the number that could be produced if none was lost during spermatogonial multiplication, meiotic maturation or spermiogenesis (Huckins, 1978). The failure of the testis to maintain the proliferation and maturation of the germ cells at full efficiency is due to spontaneous germ cell degeneration, a phenomenon described by Regaud (1900) and now recognized to be a common, if not universal, feature of the mammalian testis (Roosen-Runge, 1955, 1973; Clermont, 1972; de Kretser \& Kerr, 1988). With the availability of methods for classifying the cellular associations or stages of the cycle of the seminiferous epithelium in rats and other mammals (Leblond \& Clermont, 1952; Clermont, 1972) it is known that there are several critical steps in germ cell development where significant cell loss occurs. Among the spermatogonia of the rat testis, Clermont (1962) and Oakberg (1956) reported that $A_{2}, A_{3}$ and $A_{4}$ types may undergo necrosis when they divide mitotically. The $A_{1}-$, intermediate (In-) and $B$-type spermatogonia rarely die at the time of mitosis (Huckins, 1978). Degeneration of dividing primary and secondary spermatocytes is also recognized and in human testes this cellular attrition contributes significantly to the reduction in the theoretical yield of spermatids (Barr et al., 1971; Johnson et al., 1984). A similar phenomenon occurs in the mouse (Oakberg, 1956) and rat testis (Clermont, 1962; Russell \& Clermont, 1977). Degenerations among the germ cells may also occur during spermiogenesis in the rat; in particular step 10 and 11 elongating spermatids may fail to continue their development (Roosen-Runge, 1955; Oakberg, 1956; Clermont, 1962).

Degenerating spermatogonia, spermatocytes and round spermatids can be identified in histological sections of the testis as pyknotic bodies and degenerating elongated (step 19) spermatids can 
be detected within the body or base of the Sertoli cells (Russell \& Clermont, 1977; Kerr \& de Krester, 1975; Russell et al., 1981; Bartlett et al., 1986; Kerr \& Sharpe, 1989). In this study we used the stage classification of rat seminiferous epithelium (Leblond \& Clermont, 1952) as applied to sections embedded in plastic (Kerr et al., 1984; Kerr, 1988; Hess, 1990) and attempted to identify the stages of the spermatogenic cycle in the normal testis that show evidence of germ cell degeneration together with a quantitative estimation of variations in the relative frequency of degeneration.

\section{Materials and Methods}

\section{Animals and tissue fixation}

Testicular tissues were derived from eight adult Sprague-Dawley rats used as controls in various experiments in the last 5 years. The criteria for selection were (i) age in the range 90-120 days and body weight $300-400 \mathrm{~g}$, (ii) littermates were not used, (iii) testes in the range of $1.2-1.6 \mathrm{~g}$ after fixation, (iv) normal seminal vesicle and epididymal weight and peripheral testosterone concentration in the normal range $\left(1-5 \mathrm{ng} \mathrm{ml}^{-1}\right)$ and $(\mathrm{v})$ satisfactory tissue fixation in which the seminiferous tubules and intertubular tissue appeared qualitatively normal. Testes were perfusion-fixed (Kerr, 1988) with either $3 \%$ glutaraldehyde, $2 \%$ formaldehyde and $0.01 \%$ picric acid buffered in 0.1 mol sodium cacodylate $1^{-1}, \mathrm{pH} 7.4$ or with $3 \%$ glutaraldehyde buffered in 0.1 mol collidine $\mathrm{l}^{-1}, \mathrm{pH} 7 \cdot 4$. The fixed testes were weighed, cut into $2 \mathrm{~mm}$ cubes, postfixed in osmium tetroxide, stained with uranyl acetate, dehydrated in alcohol and embedded in Epon-Araldite. Alternate left and right testes were selected from eight rats, and 19 to 28 randomly selected blocks from each testis were cut at $1 \mu \mathrm{m}$ using an ultramicrotome, and the sections were then stained with toluidine blue. Blocks were oriented in the embedding moulds such that transverse sections through the seminiferous tubules would be seen by light microscopy.

\section{Histological assessment}

Each section was examined with a 40/1.30 oil immersion lens and round or polygonal seminiferous tubules were classified at the various stages of the cycle of the seminiferous epithelium. Stages IV-V and X-XI were combined since some tubules showed features that were either late IV or early V and late X or early XI. Degenerating germ cells were visible as deeply-stained pyknotic bodies representing spermatogonia, primary or secondary spermatocytes or round (step 1-7) spermatids. Although these pyknotic bodies could often be identified as one of these particular cell types using their location, size, density and colour, this was not always possible. The total number of degenerating germ cells in each of the stages therefore includes a very small proportion of cells the identity of which could not be established with certainty, i.e. they were too condensed or deeply basophilic making identification impossible by light microscopy. On the basis of previous investigations of germ cell abnormalities in sections embedded in plastic (Kerr \& Sharp, 1989; Sharpe et al., 1990), particular care was taken at stage IX when the residual bodies of spermatids could have been mistaken for degenerating germ cells. Residual bodies contain dense aggregations of ribosomes together with several weakly stained lipid inclusions and empty vacuoles that tend to persist as characteristic features of disintegrating residual bodies thus distinguishing them from the degenerating germ cells (Kerr \& de Kretser, 1975; Russell et al., 1981; Kerr et al., 1984). Step 19 spermatids were also included in the scores for degenerating cells; at times these failed to be released from the seminiferous epithelium at stage VIII and were retained within the cytoplasm of the Sertoli cell. The number of degenerating cells was measured within 2103 cross-sectioned tubules. The raw counts were corrected for section thickness and diameter of individual degenerating figures using Abercrombie's (1946) formula. Data were expressed as the mean \pm SEM for each stage within a testis and the mean \pm SEM was then calculated for all eight testes.

\section{Results}

No degenerating germ cells or abnormal elongated spermatids were seen at stages II-VI inclusive. At stage VII one degenerating pachytene primary spermatocyte was observed (Fig. 1a) and in another testis one step 19 spermatid was seen in the basal region of the Sertoli cell. At stages VIII-IX degenerating step 19 spermatids and basally located pyknotic germ cells were encountered (Fig. lb,c). Pyknotic bodies probably representing degenerated spermatogonia or leptotene primary spermatocytes were observed at stages X-XI and the heads or flagellae of retained step 19 elongated spermatids were also seen within the basal aspect of the seminiferous epithelium. Degenerating primary spermatocytes were a more common feature at stages XII-XIV (Fig. Id, e). 

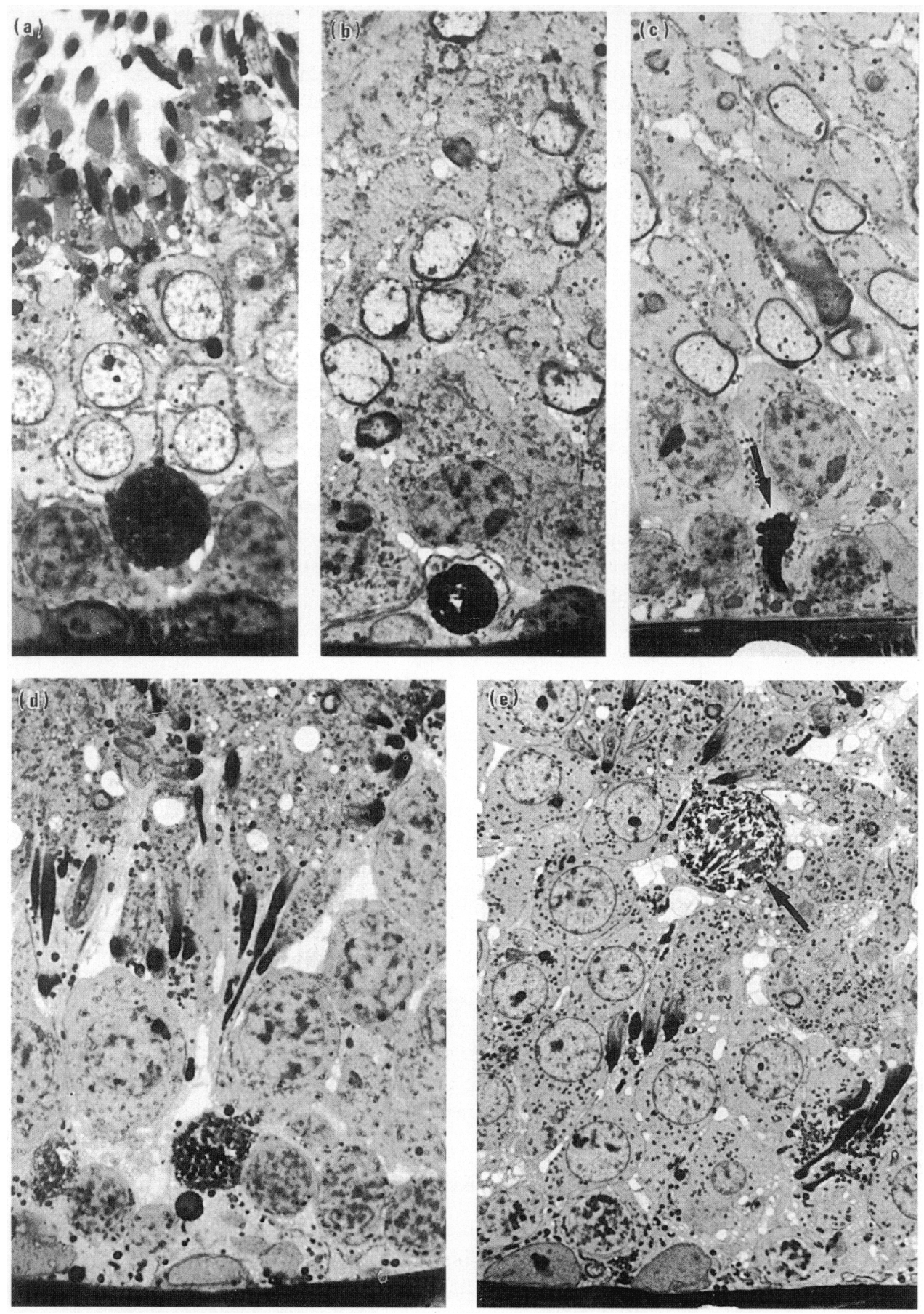

Fig. 1. (a) A degenerating pachytene primary rat spermatocyte in a stage VII tubule $(\times 1115)$. (b) A degenerating germ cell, possibly a preleptotene primary rat spermatocyte, in a stage VIII tubule $(\times 1190)$. (c) A stage IX tubule illustrating retention of the nucleus of a step 19 rat spermatid (arrow) the flagellum of which is not in the plane of section $(\times 1080)$. (d) A degenerating germ cell, probably a zygotene primary rat spermatocyte, in a stage XII tubule $(\times 1050)$. (e) A late stage XIV tubule, showing circular secondary rat spermatocytes with randomly arranged mitochondria, together with a degenerating primary rat spermatocyte containing metaphase chromosomes (arrow) and condensed granular matter $(\times 875)$. 
These were identified by their position, size and dense granularity, and the characteristic condensation of their chromatin material. Degenerating primary spermatocytes undergoing division were noted at stage XIV (Fig. 1e) exhibiting characteristic chromosomes and remnants of the spindle apparatus. At stage I, pyknotic bodies deep within the epithelium were representative of degenerating $\mathrm{A}_{4}$ mitotic spermatogonia or early pachytene primary spermatocytes. When the number of tubules showing one or more degenerating figures was compared with the total number of tubules counted at each stage, only one in approximately 200 tubules at stage VII contained degenerating figures. Similar calculations for stages VIII-I inclusive showed that this proportion was always greater, with maximum values occurring at stages XIV-I where on average, one in every three or four tubules showed pyknotic germ cells.

A comparison of the mean numbers of degenerating germ cells of all types (with circular profiles corrected for differences in mean diameter) per cross-sectioned seminiferous tubule is presented in Fig. 2, where with the exception of stages I1-VI, all other stages of the spermatogenic cycle showed spontaneous germ cell degeneration. The lowest incidence occurred at stage VII where only one pachytene primary spermatocyte and one step 19 spermatid, in different testes, were seen to be degenerating in 366 tubules. Pyknotic germ cells were also seen infrequently at stages VIII and IX ( $n=228$ tubules) comprising one degenerating spermatocyte, one degenerating spermatid and seven degenerating step 19 spermatids. At stages I and XIV, the mean number of degenerating germ cells was 14 to 40 times greater than that at stage VII.

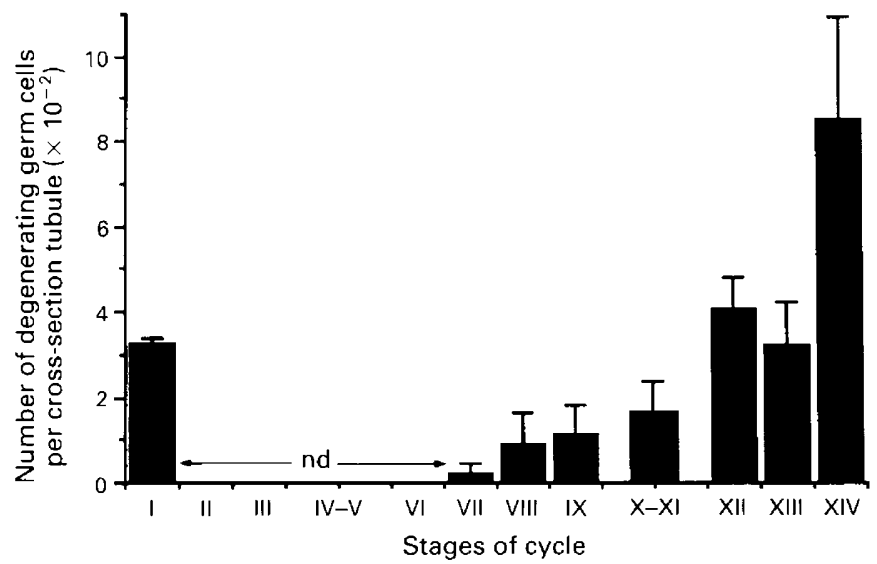

Fig. 2. Corrected number of degenerating rat germ cells per cross-sectioned seminiferous tubules at indicated stages. Data represent means \pm SEM; nd: not detected.

\section{Discussion}

The data presented show that (i) degenerating germ cells are visible by light microscopy at all stages of the spermatogenic cycle except at stages II-VI, (ii) the frequency of degeneration is lowest at stage VII and (iii) the mean number of germ cell degenerations per cross-sectioned tubule at stage VII is lower than previously reported. In the few studies that have quantified germ cell degeneration in $1 \mu \mathrm{m}$ epoxy resin sections of normal adult rat testis (Russell \& Clermont, 1977; Russell et al., 1981; Sharpe et al., 1988a, b) data are available only for stages VII, VIII-IX and XII-XIII combined, XIV and I with ten different types of germ cell said to undergo spontaneous degeneration. In the present study stages II-VI, VIII and IX individually and X-XI combined can be added to the above analysis. The measurements of degenerating germ cells at stages XI-I are in agreement with these earlier studies in respect of the types of germ cell showing pyknotic changes, that is spermatogonia types $\mathrm{A}_{2}, \mathrm{~A}_{3}$ and $\mathrm{A}_{4}$ and dividing primary and secondary spermatocytes. 
The extent of germ cell degeneration was least at stages VII-IX with VII showing the lowest mean frequency of approximately one pyknotic cell per 200 tubules (raw counts), which is about ten times lower than previous estimates (Russell \& Clermont, 1977; Russell et al., 1981; Sharpe et al., 1988b). This very low incidence confirms the subjective impression of the usual qualitative morphology of a stage VII seminiferous tubule in which pyknotic bodies are rarely encountered. In contrast, degenerating germ cells are seen more often when examining stages $\mathrm{X}-\mathrm{XIII}$ and this has been confirmed by the present quantitative analysis where approximately $10-15$ in every 100 randomly selected tubules showed pyknotic germ cells. The highest level of germ cell death occurs at stage XIV and to a lesser extent at stage I, some of which are spermatogonia and many of which are spermatocytes unable to complete one of the two meiotic divisions occurring at stage XIV of the spermatogenic cycle.

The results show that as the germ cells proliferate and mature through the process of spermatogenesis, they are most likely to degenerate at stage XIV and least likely to do so at stage VII. Similar observations have been reported in the normal rat testis by Sharpe et al. (1988b) where the numbers of degenerating germ cells per cross-sectioned tubule at stages XII-XIII and XIV-I were approximately 20 times more frequent than in stage VII. Nevertheless stage VII of the spermatogenic cycle is known to be an especially 'vulnerable step' where following loss or deprivation of hormonal stimulation, the pachytene primary spermatocyte, the step 7 spermatid and the step 19 elongated spermatid are considered to be at risk of degeneration (Russell, 1983). Spontaneous germ cell degeneration in the testes of younger rats (body weight 225-300 g) was reported to be twice as frequent at stage VII than at stage XIV (Russell et al., 1981). In contrast, in this study the examination of over 360 tubules at stage VII, taken from eight normal adult rats (body weight $300-400 \mathrm{~g}$ ), revealed only two degenerating figures.

The pattern of germ cell degeneration in the normal rat seminiferous epithelium is significantly altered when the availability of testosterone is reduced (Russell \& Clermont, 1977; Russell et al., 1981; Sharpe et al., 1988a, b) or completely withdrawn (Bartlett et al., 1986; Sharpe et al., 1990) when germ cells at stage VII are the first to degenerate and do so in large numbers compared with all other stages. These findings suggest that stage VII in particular acutely depends upon an adequate supply of testosterone which is why in this investigation the normal androgenic status of each rat was confirmed by measurement of testis, epididymal and seminal vesicle weights together with testosterone concentrations in serum. The selection of animals with other than a normal adult androgenic status may influence the pattern of spontaneous germ cell degeneration. In summary, the results show that germ cells in the adult rat testis rarely degenerate at stage VII of the seminiferous epithelial cycle and are most likely to undergo degeneration at stage XIV.

Supported by a grant from the National Health and Medical Research Council of Australia. Technical assistance by $\mathrm{S}$. Birchall is gratefully acknowledged.

\section{References}

Abercrombie, M. (1946) Estimation of nuclear population from microtome sections. Anatomical Record 94, 238-244.

Barr, A.B., Moore, D.J. \& Paulsen, C.A. (1971) Germinal cell loss during human spermatogenesis. Journal of Reproduction and Fertility 25, 75-80.

Bartlett, J.M.S., Kerr, J.B. \& Sharpe, R.M. (1986) The effect of selective destruction and regeneration of rat Leydig cells on the intratesticular distribution of testosterone and morphology of the seminiferous epithelium. Journal of Andrology 7, 240-253.

Clermont, Y. (1962) Quantitative analysis of spermatogenesis of the rat: a revised model for the renewal of spermatogonia. American Journal of Anatomy 111, $111-129$.

Clermont, Y. (1972) Kinetics of spermatogenesis in mammals: seminiferous epithelium cycle and spermatogonial renewal. Physiological Reviews 52, 198-236.

de Kretser, D.M. \& Kerr, J.B. (1988) The cytology of the testis. In The Physiology of Reproduction, pp. 837-932. Eds E. Knobil \& J. Neill. Raven Press, New York.

Hess, R.A. (1990) Quantitative and qualitative characteristics of the stages and transitions in the cycle of the rat seminiferous epithelium: light microscopic 
observations of perfusion-fixed and plastic-embedded testes. Biology of Reproduction 43, 525-542.

Huckins, C. (1978) The morphology and kinetics of spermatogonial degeneration in normal adult rats: an analysis using a simplified classification of the germinal epithelium. Anatomical Record 190, 905-926.

Johnson, L., Petty, C.S., Porter, J.C. \& Neaves, W.B. (1984) Germ cell degeneration during postprophase of meiosis and serum concentrations of gonadotrophins in young adult and older adult men. Biology of Reproduction 31, 779-784.

Kerr, J.B. (1988) A light microscopic and morphometric analysis of the Sertoli cell during the spermatogenic cycle of the rat. Anatomy and Embryology 179, 191-203.

Kerr, J.B. \& de Kretser, D.M. (1975) Cyclic variations in Sertoli cell lipid content throughout the spermatogenic cycle in the rat. Journal of Reproduction and Fertility 43, 1-8.

Kerr, J.B. \& Sharpe, R.M. (1989) Focal disruption of spermatogenesis in the testis of adult rats after a single administration of human chorionic gonadotrophin. Cell and Tissue Research 257, 163-169.

Kerr, J.B., Rich, K.A. \& de Kretser, D.M. (1984) Morphometric studies on lipid inclusions in Sertoli cells during the spermatogenic cycle in the rat. Cell and Tissue Research 236, 699-709.

Leblond, C.P. \& Clermont, Y. (1952) Definition of the stages of the cycle of the seminiferous epithelium in the rat. Annals of New York Academy of Sciences 55, $548 \cdots 573$.

Oakberg, E. (1956) A description of spermatogenesis in the mouse and its use in analysis of the cycle of the seminiferous epithelium and germ cell renewal. American Journal of Anatomy 99, 391-413.

Regaud, C.P. (1900) Dégénérescence des cellules seminales chez les mammifères en l'absence de tont état pathologique. Comptes Rendus des Seances de la Societé de Biologie 52, 268-270.
Roosen-Runge, E.C. (1955) Untersuchungen uber die degeneration samenbildener zellen in der normaler spermatogenese der ratte. Zeitschrift für Zellforschung und Mikrosopische Anatomie 41, 221-225.

Roosen-Runge, E.C. (1973) Germinal cell loss in normal metazoan spermatogenesis. Journal of Reproduction and Fertility 35, 331-348.

Russell, L.D. (1983) Normal testicular structure and methods of evaluation under experimental and disruptive conditions. In Reproductive and Developmental Toxicity of Metals, pp. 227-252. Eds T. W. Clarkson, G. F. Nordberg \& P. R. Sager. Plenum Press, New York.

Russell, L.D. \& Clermont, Y. (1977) Degeneration of germ cells in normal, hypophysectomized and hormone treated hypophysectomized rats. Anatomical Record 187, 347--366.

Russell, L.D., Malone, J.P. \& Karpas, S.L. (1981) Morphological pattern elicited by agents affecting spermatogenesis by disruption of its hormonal stimulation. Tissue and Cell 13, 369-380.

Sharpe, R.M., Donachie, K. \& Cooper, I. (1988a) Reevaluation of the intratesticular level of testosterone required for quantitative maintenance of spermatogenesis in the rat. Journal of Endocrinology 117, 19-26.

Sharpe, R.M., Fraser, H.M. \& Ratnasooriya, W.D. (1988b) Assessment of the role of Leydig cell products other than testosterone in spermatogenesis and fertility in adult rats. International Journal of Andrology 11, 507-523.

Sharpe, R.M., Maddocks, S. \& Kerr, J.B. (1990) Cell-cell interactions in the control of spermatogenesis as studied using Leydig cell destruction and testosterone replacement. American Journal of Anatomy 188, 3-20.

Received 26 June 1991 